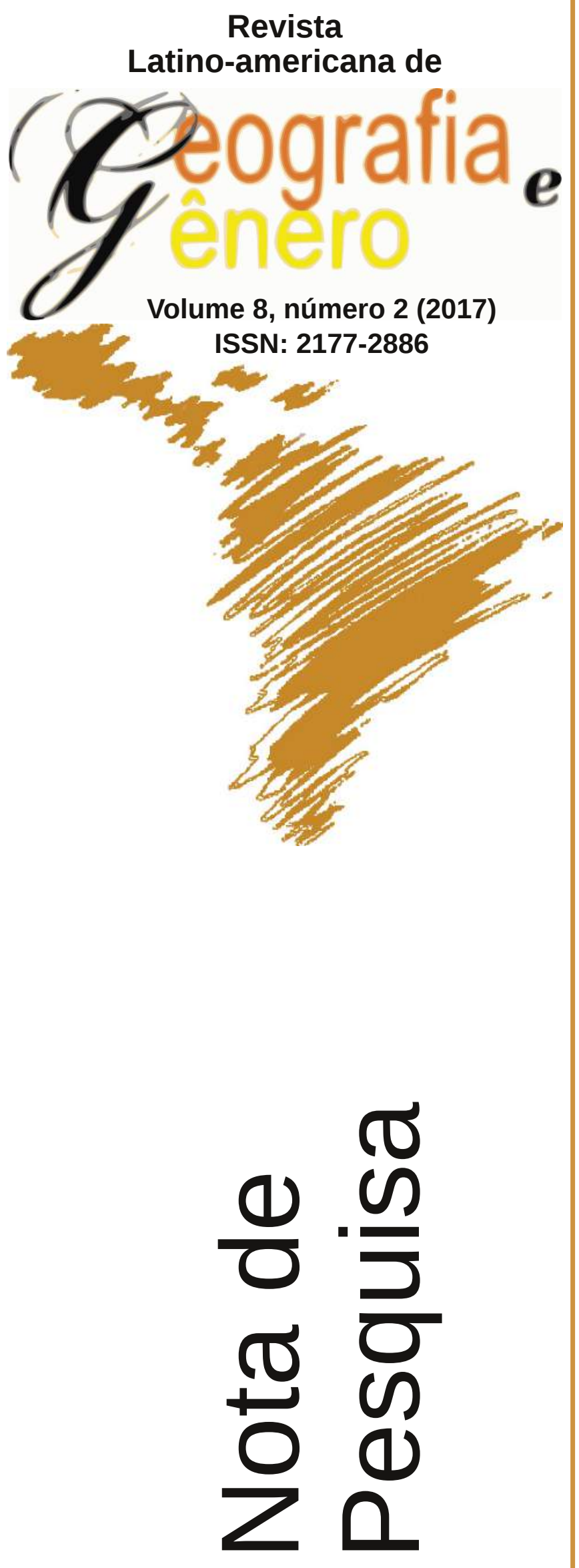

\title{
Técnicas de Análise de Conteúdo: Experiências de Pesquisas Desenvolvidas pelo Grupo de Estudos Territoriais
}

Técnicas de Análisis de Contenido: Experiencias de Investigación Desarrolladas por el Grupo de Estudios Territoriales

Techniques of Content Analysis: Research Experiences Developed by Territorial Studies Group

\section{Edson Armando Silva}

Universidade Estadual de Ponta Grossa - Brasil edameister@gmail.com

João Paulo Leandro de Almeida

Universidade Estadual de Ponta Grossa - Brasil jplagete@gmail.com

\section{Joseli Maria Silva}

Universidade Estadual de Ponta Grossa - Brasil joseli.genero@gmail.com

\section{Mayã Polo de Campos}

Universidade Estadual de Ponta Grossa - Brasil mayapcampos@gmail.com

Como citar este artigo:

SILVA, Edson Armando; ALMEIDA, João Paulo Leandro de; SILVA, Joseli Maria; CAMPOS, Mayã Polo de. Técnicas de Análise de Conteúdo: Experiências de Pesquisas Desenvolvidas pelo Grupo de Estudos Territoriais. Revista Latino Americana de Geografia e Gênero, v. 8, n. 2, p. 401-425, 2017. ISSN 2177-2886.

Disponível em:

http://www.revistas2.uepg.br/index.php/rlagg 


\section{Esclarecimentos Iniciais}

Nossas metodologias devem ser coerentes com nosso posicionamento teórico e epistemológico e essa coerência deve ser demonstrada concretamente nos procedimentos que realizamos. Portanto, a transparência e a discussão sobre os procedimentos de pesquisa devem ser parte da demonstração das nossas hipóteses. Para nós a ciência não é neutra, mas produzida por pessoas de carne e osso em tempos e espaços com determinado alcance de recursos materiais e culturais. Assim, a forma como construímos os dados da pesquisa é de fundamental importância para obter o reconhecimento da produção de um conhecimento que seja considerado científico. Ackerly e True (2010, p. 25) sustentam a ideia de que a "epistemologia é um sistema de pensamento que nós usamos para distinguir fato de crença. Uma epistemologia é ela mesma um sistema de crenças sobre o que constitui conhecimento, evidência e argumento convincente". Sendo a epistemologia o fundamento dos nossos postulados teóricos é preciso legitimar os argumentos de um conhecimento pretendido como científico explicitando a metodologia e demonstrando sua coerência com os seus fundamentos teóricos.

As epistemologias feministas têm séria preocupação com a criação dos modelos analíticos da realidade, já que se fundamentam na ideia do 'conhecimento situado', proposto por Haraway (1988). Para ela, não existe a possibilidade de criação de conhecimento que não seja 'situado e corporificado'. Ainda mais, ela advoga a ideia de que os conhecimentos não localizáveis não passam de mitos narrados na história científica para consagrar a ideia de superioridade do saber que tudo sabe e tudo vê. Finalmente afirma que a alternativa às totalizações é a construção de saberes parciais, localizados, críticos, que formem redes de conexões e articulem a política e a epistemologia.

Portanto, é fundamental para nós considerar a posição da pessoa que cria o conhecimento, os caminhos que adota, e compreender os resultados da pesquisa a partir dessa trajetória. Assim deixar explícita a trajetória de construção do modelo de análise é não apenas ético, mas necessário para garantir a objetividade do conhecimento produzido. Nossa postura como pesquisadores é de que nossos procedimentos devem ser compatíveis com compreensão de ciência que adotamos. Assim, se adotamos a ideia de que a ciência deve ser produzida de forma comprometida com a superação das injustiças e hierarquias, as ações do/a Pesquisador/a devem refletir esse processo de fazer científico. Por exemplo, de nada adianta escrever a célebre frase repetida em tantos textos científicos 'esta pesquisa pretende dar voz aos grupos excluídos' e, posteriormente adotar uma atitude arrogante de apenas escolher trechos de fala das pessoas colaboradoras para sustentar minhas próprias ideias, ou ainda, para adequar os dados aos conceitos acadêmicos escolhidos.

Nossa postura de humildade científica implica superar a posição 'do olho de deus' capaz de criar as verdades sobre a realidade do grupo social investigado e criar mecanismos para 'interpretar como eles próprios compreendem sua realidade espacial'. Só assim a pesquisa poderá ser um canal de expressão das 
realidades de grupos sociais vulnerabilizados. A pesquisa 'não dá a voz' a esses grupos, mas deve construir caminhos de enunciação compartilhada.

A apresentação de nossa proposta metodológica está estruturada em três seções. Na primeira seção discutimos a importância de produzir um claro fio condutor da pesquisa para que as demais etapas, dependentes desta, possam ser solidamente traçadas. Na segunda seção evidenciamos a relação entre o fio condutor estabelecido (ou aquilo que se quer conhecer) e as fontes que, no caso desta exposição, são grupos de pessoas que estabelecem um diálogo com o/a pesquisador(a). Na terceira e última seção explicamos o tratamento analítico das informações produzidas em conjunto com nossas fontes, demonstrando as formas de operacionalização do conteúdo discursivo. Esta última seção está dividida em três etapas principais: a preparação do conteúdo discursivo para realização do tratamento de análise de conteúdo, a criação do mapa mental com as categorias discursivas e por fim, o desenvolvimento das redes semânticas do discurso. Para cada uma dessas etapas são demonstrados os passos para operacionalizar a etapa e os procedimentos a serem realizados nos softwares específicos indicados.

\section{Criando o Fio Condutor para a Elaboração do Modelo de Análise}

Não se pode criar um modelo de análise sem ter uma questão a ser respondida e se estabelecer o conjunto de fontes discursivas a serem trabalhadas. Pensar em metodologia significa criar um modelo para operacionalizar as respostas para uma Questão Central de pesquisa (SILVA, SILVA e JUNCKES, 2009). Só quando se tem uma pergunta clara, exequível e pertinente é que se pode prosseguir para o momento de pensar 'como' vou responder a questão elaborada. Além disso, é também da Questão Central bem estabelecida que se encontra o caminho conceitual para construir a 'problemática de pesquisa'.

\section{Exemplos de Questões Centrais já Resolvidas no Âmbito do Grupo de Estudos Territoriais que Conduziram o Raciocínio para a Elaboração de Modelos de Análise}

Observe os exemplos que seguem: a questão central possui eixos estruturadores que devem servir de guia para constituir as subquestões específicas. Cada um dos eixos estruturadores estão marcados em diferentes cores para facilitar o reconhecimento. Obs: Nunca abra novas questões que não estejam embutidas na questão central. Os exemplos que se seguem são de pesquisas já elaboradas no âmbito do Grupo de Estudos Territoriais ${ }^{1}$.

- Exemplo 1: capítulo de livro escrito por Joseli Maria Silva, Maria Rodó de Zárate e Marcio Jose Ornat (forthcoming).

1 Trabalhos disponíveis em http://www.gete.net.br/ na aba 'produções'. 
Técnicas de Análise de Conteúdo: Experiências de Pesquisas Desenvolvidas

pelo Grupo de Estudos Territoriais

Questão Central: Como o reconhecimento da velhice dos corpos travestis e transexuais femininas trabalhadoras sexuais brasileiras estabelecem diferentes interseccionalidades entre gênero, sexualidades e espaços?

Sub-questões:

- Como se constituem as percepções da velhice no grupo?

- De que forma a inteligibilidade de corpos travestis e transexuais se constitui na etapa da velhice?

- Como as experiências espaciais de travestis e transexuais femininas na etapa da velhice transformam as relações interseccionais de gênero e sexualidades?

Conceitos centrais que esta questão exige:

Envelhecimento; interseccionalidades; espaço.

Grupo capaz de produzir as informações necessárias para construir a resposta à questão estabelecida:

Travestis e transexuais femininas, trabalhadoras sexuais brasileiras.

- Exemplo 2: tese de doutorado de Rodrigo Rossi (2017).

Questão Central: De que forma se instituem as masculinidades de homens jovens no cotidiano da espacialidade carcerária em Ponta Grossa - PR?

Sub-questões:

Como as trajetórias dos homens jovens compõem as masculinidades instituídas no cotidiano carcerário?

Como o espaço carcerário se faz da normatividade específica de masculinidade?

Como as práticas cotidianas dos homens instituem a espacialidade carcerária?

Conceitos centrais que esta questão exige:

Masculinidades; espaço; cárcere; cotidiano.

Grupo capaz de produzir as informações necessárias para construir a resposta à questão estabelecida:

Jovens homens detentos ou ex-detentos

- Exemplo 3: dissertação de mestrado de Mayã Pólo de Campos (2016)

Questão Central: Como as mulheres significam a relação entre corpo e espaço a partir da experiência da violência sexual?

Sub-questões:

Como as mulheres vítimas de violência sexual constituem representações sobre si mesmas?

Como as experiências corporais são representadas no discurso das mulheres vítimas de violência sexual?

Edson Armando Silva, João Paulo Leandro de Almeida, Joseli Maria Silva, Mayã Polo de Campos 
Técnicas de Análise de Conteúdo: Experiências de Pesquisas Desenvolvidas

pelo Grupo de Estudos Territoriais

Como o espaço é instituído pela experiência das mulheres vítimas de violência sexual?

Conceitos centrais que esta questão exige:

Gênero/feminilidades; Corpo; Espaço; Violência sexual.

Grupo capaz de produzir as informações necessárias para construir a resposta à questão estabelecida:

Mulheres que sofreram a experiência da violência sexual.

- Exemplo 4: trabalho de conclusão de curso de Vagner André Morais Pinto (2014)

Questão Central: Como o gênero compõe o perfil da produção científica entre docentes pesquisadores no espaço acadêmico da Universidade Estadual de Ponta Grossa?

Sub-questões:

Qual é o perfil de produção científica entre homens e mulheres no campo da Geografia no Brasil?

Como o exercício dos papéis masculinos e femininos incide na organização do tempo na produção científica de artigos acadêmicos?

Como as espacialidades implicam as relações entre gênero e o processo de produção científica?

Conceitos centrais que esta questão exige:

Gênero; Produção científica; Espaço acadêmico.

Grupo capaz de produzir as informações necessárias para construir a resposta à questão estabelecida:

Pesquisadores homens e mulheres que atuam em espaço acadêmico

- Exemplo 5: tese de doutorado de Juliana Przybysz (2017)

Questão Central: Como se estabelecem as espacialidades de mulheres prostitutas no exercício de maternagens?

Sub-questões:

Como se institui o processo de identificação profissional do sexo?

Como se estabelecem as diferentes formas de prostituição que implicam variadas configurações de maternagem?

Como a interseccionalidade entre maternagens e a atividade da prostituição constituem espacialidades femininas?

Conceitos centrais que esta questão exige:

Gênero; Prostituição; Espaço; Interseccionalidades.

Grupo capaz de produzir as informações necessárias para construir a resposta à questão estabelecida:

Mulheres prostitutas mães.

Edson Armando Silva, João Paulo Leandro de Almeida, Joseli Maria Silva, Mayã Polo de Campos 
Técnicas de Análise de Conteúdo: Experiências de Pesquisas Desenvolvidas

pelo Grupo de Estudos Territoriais

\section{Estabelecendo o Roteiro para Entrevistas com o Grupo Selecionado como Fonte Discursiva}

Uma vez que a questão central esteja bem estabelecida e o recorte da fonte discursiva a ser acessada também esteja clara, é necessário pensar em 'como obter as informações necessárias das fontes'. Nos casos tomados como exemplo, as fontes são grupos de pessoas.

Além do cuidado com a contextualização da pessoa que está colaborando com a pesquisa e do fenômeno em tela, deve-se elaborar instrumentos de pesquisa que sejam capazes de responder o que você busca. No caso de a melhor opção ser um roteiro de pesquisa deve-se ter 'total atenção' para construir as respostas às questões específicas elaboradas no seu guia de investigação. Lembre-se que sua tese ou dissertação deverá construir a respostas às questões de pesquisa elaboradas por você e portanto, é com os dados produzidos na relação com o grupo que você terá condições de interpretar a realidade que você questionou.

Assim, é importante 'testar' seu roteiro com algumas pessoas do grupo que colaborará com a pesquisa e que se disponha a criticar o seu documento. Depois, reorganize seu roteiro conforme as argumentações e só daí prosseguir com suas entrevistas.

Veja o exemplo de roteiro que cobre as questões estabelecidas descritas no exemplo 1, anteriormente evidenciado. Lembrando o exemplo 1:

Questão Central: Como o reconhecimento da velhice dos corpos travestis e transexuais femininas trabalhadoras sexuais brasileiras estabelecem diferentes interseccionalidades entre gênero, sexualidades e espaços?

Sub-questões:

- Como se constituem as percepções da velhice no grupo?

- De que forma a inteligibilidade de corpos travestis e transexuais se constitui na etapa da velhice?

- Como as experiências espaciais de travestis e transexuais femininas na etapa da velhice transformam as relações interseccionais de gênero e sexualidades?

Então, são as sub-questões estabelecidas que devem guiar a elaboração do roteiro de entrevista. Afinal, o roteiro é o meio que possibilita a forma de como a fonte discursiva será acessada.

- Roteiro de entrevista

Data:

Local de realização:

Autorização de uso da fala:

- Identificação da pessoa entrevistada

Nome fictício:

Idade: 
Técnicas de Análise de Conteúdo: Experiências de Pesquisas Desenvolvidas

pelo Grupo de Estudos Territoriais

Como se apresentaria (gênero/sexualidade):

Como consegue recursos para sobreviver:

Como é um dia de sua vida?

Quais são os espaços que usa cotidianamente?

- Relação entre velhice e espaço

- Qual a razão que te levou a considerar-se velha? Quando esse processo se iniciou?

- Que fatores físicos e de saúde você poderia apontar?

- Quais as percepções em suas relações sociais?

- Vc, quando jovem imaginava ou se projetava na velhice? Porque?

- Como você acha que outras travestis te percebem?

- Como você acha que outras pessoas te interpretam? Vc acha que a forma como as pessoas te interpretam e tratam mudou?

- Quais as coisas que se modificaram em sua vida a partir do momento que você se vê como velha? No trabalho, nas amizades, na família/casamento e também com outras instituições como hospitais, polícia e escola?

- Em sua avaliação em que aspectos de sua vida houve melhora ou piora com a velhice?

- Como você age para superar os obstáculos que você está enfrentando em sua velhice?

- Quais são as pessoas que te apoiam ou dão assistência em suas dificuldades com os problemas da velhice? (econômicos, saúde, emocional)

- Como você desenvolveu suas ações para segurança no período da velhice?

- Quais os aspectos da velhice que te amedrontam?

- Quais as expectativas de futuro em sua velhice?

Depois do roteiro testado, as entrevistas devem ser realizadas e transcritas na íntegra. Até aqui estes procedimentos têm sido comum entre pesquisadores/as. O desafio começa quando se tem uma massa de informações e a necessidade de interpretação do material coletado.

No GETE partimos da proposta de análise de conteúdo, apresentada por Laurence Bardin (1977) e desenvolvemos procedimentos técnicos para sua operacionalização, publicados inicialmente em SILVA e SILVA (2016).

A análise de conteúdo para Bardin (1977) se constitui em um conjunto de instrumentos metodológicos que se aplicam aos discursos. $\mathrm{O}$ fator comum das técnicas é promover uma interpretação controlada que se baseia na inferência. A inferência seria então algo que vai além da compreensão literal de uma informação dada, pode ser definida como a conclusão ou um julgamento tirado dessa informação. Ao final dos procedimentos teremos uma rede semântica da fala do grupo ou de documentos textuais, constituída da RELAÇÃO entre depoentes e pesquisadores/as que produziram conjuntamente o conhecimento.

\section{A Transformação das Entrevistas em Informações para Interpretação}

Depois que o conteúdo discursivo foi transcrito e estando de posse de um texto escrito que são as informações construídas em conjunto com suas fontes, 
Técnicas de Análise de Conteúdo: Experiências de Pesquisas Desenvolvidas

pelo Grupo de Estudos Territoriais

inicia-se o processo de interpretação do conteúdo discursivo. Mais uma vez, é importante ter em mente o fio condutor com a questão central e as subquestões. Veja este caso abaixo tomando como o exemplo 4 como referência:

Questão Central: Como o gênero compõe o perfil da produção científica entre docentes pesquisadores no espaço acadêmico da Universidade Estadual de Ponta Grossa?

Sub-questões:

Qual é o perfil de produção científica entre homens e mulheres no campo da Geografia no Brasil?

Como o exercício dos papéis masculinos e femininos incide na organização do tempo na produção científica de artigos acadêmicos?

Como as espacialidades implicam as relações entre gênero e o processo de produção científica?

Cada questão envolveu diferentes procedimentos metodológicos. A Última questão foi respondida por um roteiro de entrevista com 2 questões abertas que permitiam as pessoas se expressarem de forma livre: 1- "O seu papel social de gênero interfere na sua produção científica?" e 2- "O que as implicações da família representam no seu desempenho profissional?"

De posse de todo conteúdo discursivo em forma do texto obtido pela transcrição literal da fala gravada, são iniciados uma série de procedimentos de tratamento das informações. Os procedimentos metodológicos foram desenvolvidos a partir do seguinte conjunto de softwares que foram escolhidos entre aqueles 'livres' (não apenas gratuitos) e cujas características de programação pudessem ser usados nos principais sistemas operacionais do mercado $^{2}$ :

Pacote LibreOffice 5.4.4 / OpenRefine 2.0 / Gephi 0.9.1/ VUE (Visual Understanding Environment) 3.3.0/ Pacote $R$ 3.2.2 - "RQDA - Package for Qualitative Data Analysis / DB Browser for SQLITE" 3.16.0.

\section{Primeira etapa: preparando o conteúdo discursivo para construção da rede de palavras (Nesta etapa: Pacote LibreOffice / OpenRefine / Gephi)}

Esta etapa parte do pressuposto já demonstrado por Bardin (1977) de que a ênfase no uso de determinadas palavras revela sentidos comuns expressos em um conjunto discursivo. A linguagem é simultaneamente expressão e constituidora da realidade.

Pensar a frequência do uso das palavras utilizadas pelo grupo que colaborou com a pesquisa não é apenas uma contagem estatística. É perceber a incorporação as relações existentes entre os termos utilizados no conjunto discursivo e simultaneamente preservar a integridade dos dados, deixando que a fonte fale por si mesma.

2 É importante ressaltar que os procedimentos descritos estão pautados nas versões formadas e que as atualizações de versões podem acarretar mudanças de procedimentos.

Edson Armando Silva, João Paulo Leandro de Almeida, Joseli Maria Silva, Mayã Polo de Campos

Revista Latino-americana de Geografia e Gênero, Ponta Grossa, v. 8, n. 2, p. 401 - 425, ago. / dez. 2017. 
Técnicas de Análise de Conteúdo: Experiências de Pesquisas Desenvolvidas

pelo Grupo de Estudos Territoriais

Para produzir a relação entre os termos se constrói uma 'rede' em que cada nó é a palavra e a relação entre os nós (palavras) são as arestas produzidas entre as palavras que pertencem à mesma frase no discurso. A frase é, portanto, tomada como a unidade de sentido das conexões.

Passo 1: Desambiguar os termos. Uma mesma palavra pode ter significados diferentes, dependendo do contexto empregado. Ex: 'trabalho' significando trabalhar em casa e 'trabalho' significando trabalho acadêmico. Nesse caso há necessidade de desambiguar ou seja diferenciar os usos da palavra aplicando um código como 'c trabalho' e 'a trabalho'. Ou ainda quando a fala está repleta de gírias que possuem significados próprios para o grupo. Ex: 'boi' na linguagem carcerária significa 'banheiro'. Então é necessário fazer uma marcação 'banheiro_boi'. Ou quando o grupo cria estratégias para evitar algumas palavras e usam expressões genéricas. Ex: 'cara' representado um homem genérico e 'cara' referindo-se ao agressor. Então, deve colocar marcas para que os softwares leiam como sendo palavras diferentes. g_cara / a_cara. Enfim, deve ser feita uma leitura prévia do conteúdo discursivo e as marcas de desambiguação devem ser incorporadas no texto para que o computador não realize leituras equivocadas e agrupamentos que não representem os diferentes sentidos das palavras.

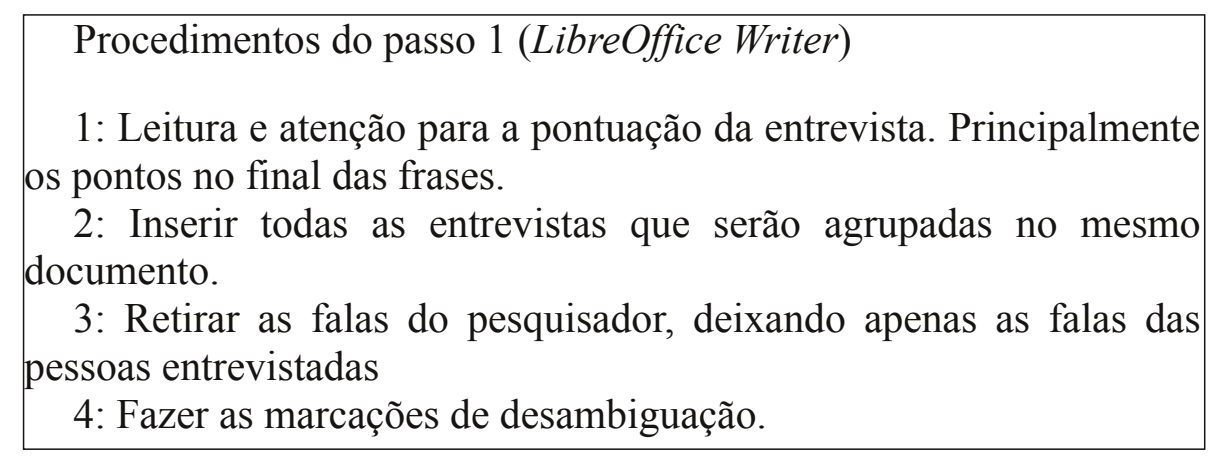

Passo 2: Padronizar todas as palavras em letras minúsculas pois para o computador não existe a 'palavra' mas um conjunto de caracteres. Letras maiúsculas e minúsculas, para o computador, são diferentes caracteres.

Procedimentos do passo 2: (LibreOffice Writer)

1: Selecione toda a entrevista $(\operatorname{Ctrl} \mathrm{A})$

2: Clique com o botão direito na entrevista e selecione a opção Alterar caixa $>$ minúsculas.

Passo 3: Constituir a frase como unidade de sentido, transformando o texto em tabela.

Procedimentos do passo 3: (Libreoffice / Writer e Calc)
1: Localizar e Substituir (ctrl F ou ctrl H) todos os pontos por
parágrafo. [\. substituir por $\backslash \mathrm{n}]$
obs: Atente-se para que cada frase se transforme em parágrafo.
Esse procedimento ao mesmo tempo que retira os pontos
desnecessários na análise coloca cada frase em um parágrafo


Técnicas de Análise de Conteúdo: Experiências de Pesquisas Desenvolvidas

pelo Grupo de Estudos Territoriais

diferente.

Obs: Para esta ação, em 'Outras opções', deixe marcado 'Expressões regulares'

2: Retire do texto todas as vírgulas, pontos de interrogação, exclamação, aspas usando os comandos localizar e substituir por espaço. Em seguida pode-se eliminar os espaços duplos. Salve uma cópia deste arquivo em formato .txt para utilizar posteriormente.

3: Para transformar texto em tabela os comandos são [Ctrl A + Tabela $>$ Inserir $>$ Tabela]

4: Inserir na tabela um cabeçalho e uma coluna do lado esquerdo. $\mathrm{Na}$ célula da primeira coluna do cabeçalho escrever Id e na célula da segunda coluna escrever Frase.

5: Selecione todo o documento [Ctrl A] e copie [Ctrl C], por fim, cole $[C t r l \mathrm{~V}]$ em um documento de planilha (Calc).

6: Numere a coluna do ID, seguindo uma ordem numérica arábica crescente até o final $(1,2,3,4,5 \ldots)$

7: Salve como texto_geral.csv que deve estar parecido com o exemplo abaixo:

\begin{tabular}{|l|l|}
\hline Identificador da Frase & Frase \\
\hline 1 & $\begin{array}{l}\text { Sim, eu divido o meu dia entre cuidar da família } \\
\text { e o trabalho. }\end{array}$ \\
\hline 2 & $\begin{array}{l}\text { Então quando eu tô em casa, tento privilegiar a } \\
\text { família e não levar trabalho pra casa, não } \\
\text { precisar fazer trabalho fora dos horários em que } \\
\text { eu teria que trabalhar. }\end{array}$ \\
\hline 3 & $\begin{array}{l}\text { E quando minhas filhas tão em casa, eu } \\
\text { privilegio as duas em vez de atender à vida } \\
\text { profissional. }\end{array}$ \\
\hline
\end{tabular}

A tabela continua assim por diante...

Passo 4 : Usar o OpenRefine para dividir frases em palavras, identificar para cada frase o seu conjunto de palavras correspondentes na tabela e eliminar pontuação, números e termos não significativos.

\begin{tabular}{|c|c|}
\hline Identificação da Frase & Frase \\
\hline 1 & sim \\
\hline & eu \\
\hline & divido \\
\hline & o \\
\hline & meu \\
\hline & dia \\
\hline & entre \\
\hline & cuidar \\
\hline & da \\
\hline & família \\
\hline & e \\
\hline & o \\
\hline & trabalho \\
\hline
\end{tabular}

Edson Armando Silva, João Paulo Leandro de Almeida, Joseli Maria Silva, Mayã Polo de Campos 
Técnicas de Análise de Conteúdo: Experiências de Pesquisas Desenvolvidas

pelo Grupo de Estudos Territoriais

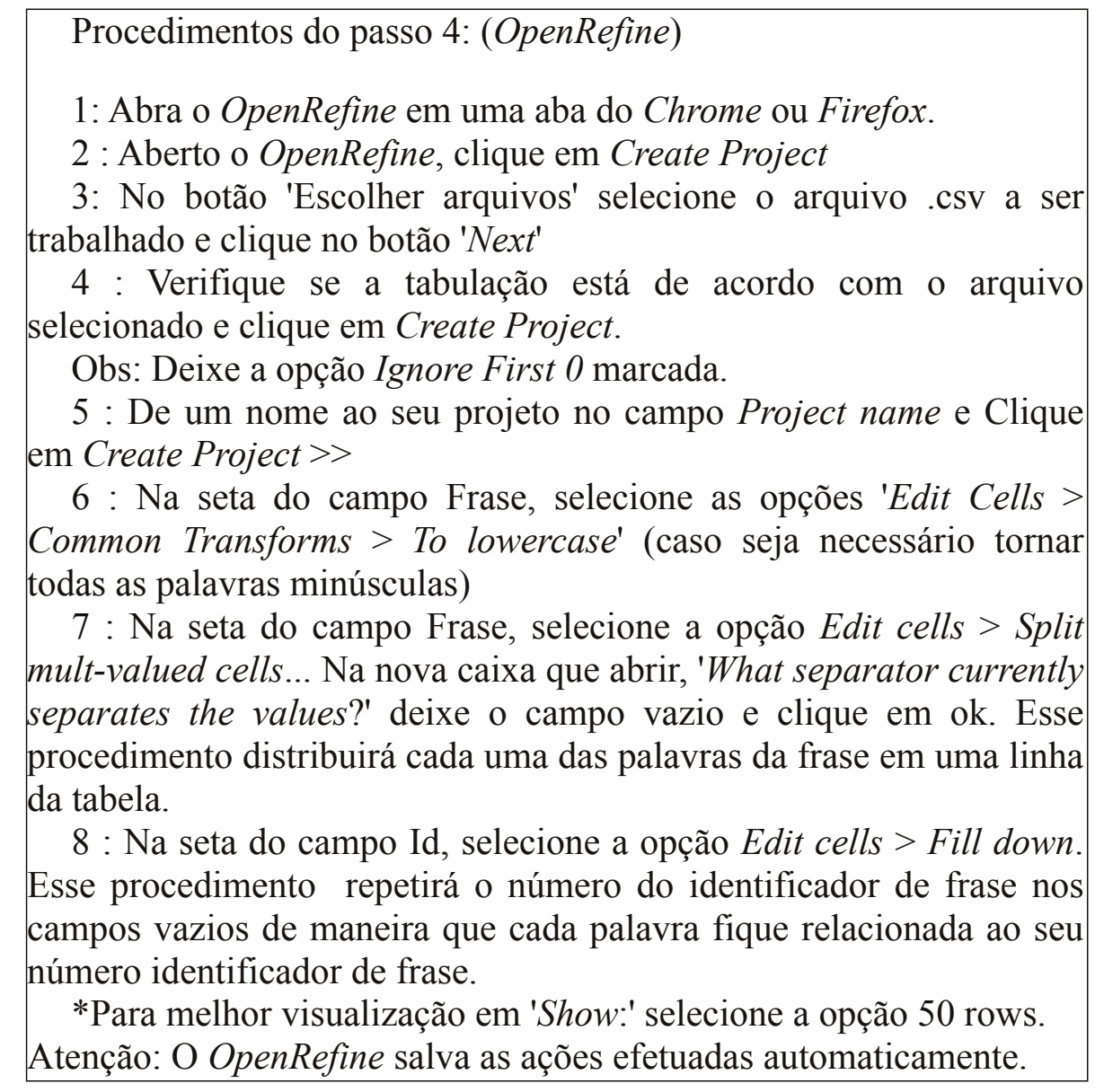

Passo 5: Para se retirar os termos não significativos existe uma forma de acelerar muito o processo. Como existem na internet listas de "stopwords" disponíveis com as quais podemos criar um "script" (realizando e gravando os procedimentos de retirada) que limpará o nosso texto de todas as palavras que existiam nessa lista. Ex: 'da' 'o' 'né'. Entretanto é necessário ter atenção: a retirada de termos considerados não significativos depende do contexto de cada discurso e por isso, além da limpeza automatizada, é necessário fazer um trabalho mais fino de limpeza manual. Por exemplo, o script pode estar preparado para remover a palavra 'para', mas possivelmente não irá remover sua forma coloquial 'pra'. Casos como este somente serão removidos com uma ação manual que, pode gerar um novo "script" especialmente preparado para a limpeza do seu conjunto de discursos.

Procedimentos do passo 5: (LibreOffice Writer e Calc, OpenRefine)

1: Encontre uma lista de stopwords em algum buscador e verifique se o vocabulário a ser excluído não contenha termos importantes para sua investigação. Lembre-se que as palavras encontradas na lista, serão excluídas das entrevistas.

2: Abra a lista em um editor de texto (Writer) selecione todo o texto e o insira em uma tabela. (Tabela $>$ Inserir $>$ Tabela).

3: Selecione toda a tabela, copie e cole em uma planilha (LibreOffice Calc)

4: Salve como .csv denominando o arquivo como stopwords 
Técnicas de Análise de Conteúdo: Experiências de Pesquisas Desenvolvidas

\section{pelo Grupo de Estudos Territoriais}

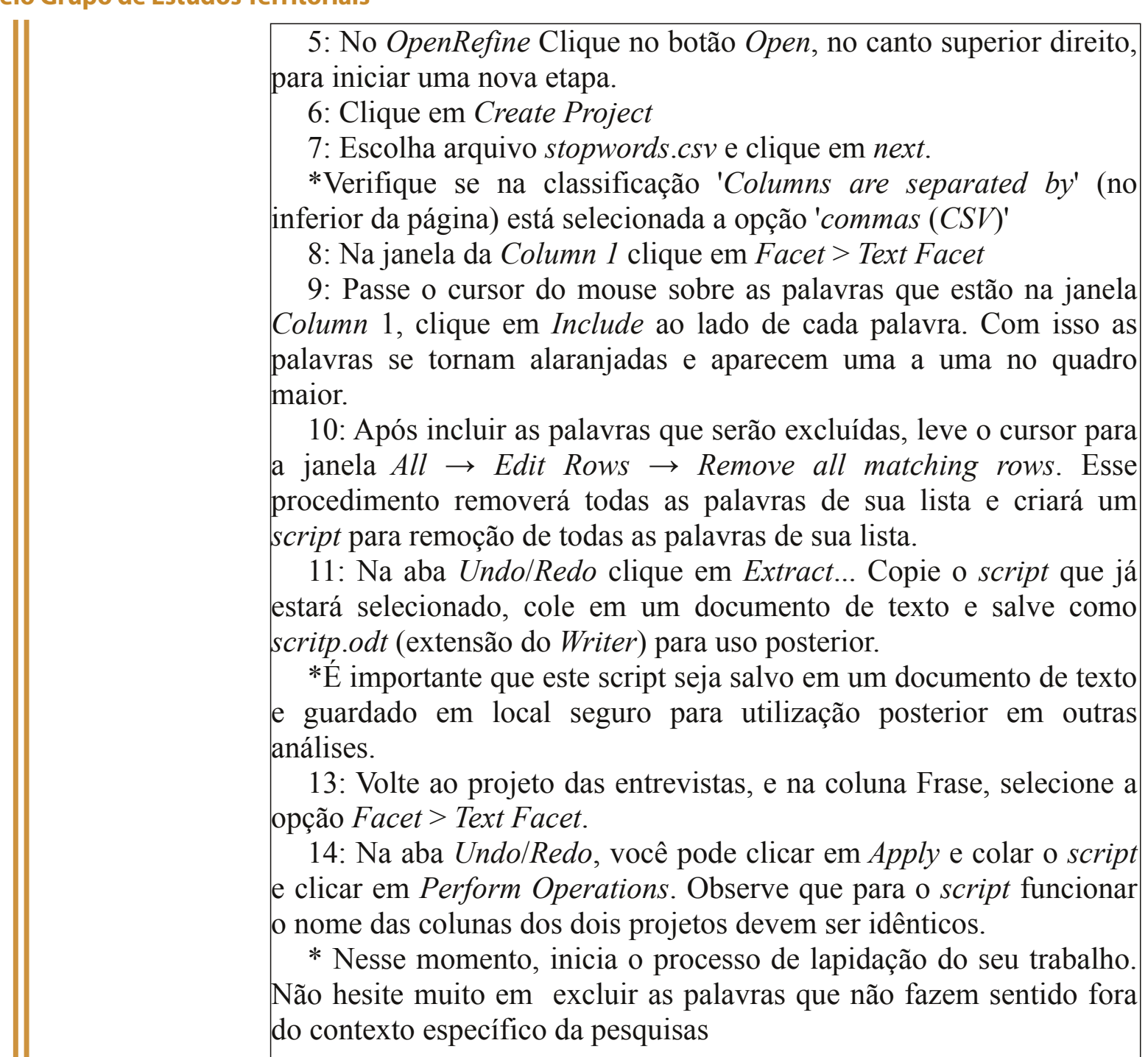

\begin{tabular}{|c|c|}
\hline Identificação da Frase & Frase \\
\hline 1 & $\operatorname{sim}$ \\
\hline 1 & divido \\
\hline 1 & dia \\
\hline 1 & cuidar \\
\hline 1 & família \\
\hline 1 & trabalho \\
\hline 2 & casa \\
\hline 2 & tento \\
\hline 2 & privilegiar \\
\hline 2 & família \\
\hline 2 & não \\
\hline 2 & levar \\
\hline 2 & trabalho \\
\hline 2 & casa \\
\hline 2 & não \\
\hline 2 & precisa \\
\hline 2 & fazer \\
\hline 2 & trabalho \\
\hline 2 & horários \\
\hline 2 & trabalhar \\
\hline
\end{tabular}

Edson Armando Silva, João Paulo Leandro de Almeida, Joseli Maria Silva, Mayã Polo de Campos 
Técnicas de Análise de Conteúdo: Experiências de Pesquisas Desenvolvidas

pelo Grupo de Estudos Territoriais

Passo 6: Padronizar termos que possuem o mesmo radical e podem ser reunidos sem perda de sentido. Ex: 'artigos' 'artigo' ou ainda 'produzir' 'produção' 'produzindo'.

\section{Procedimentos do passo 7: (OpenRefine)}

1 : Clique em 'Cluster' e agrupe as palavras com o mesmo sentido. Selecionando no quadro Method 'Key collision' e no quadro Keying Function 'fingerprint'. Você pode também fazer os agrupamentos explorando as outras opções desse quadro. Após os comandos, clique em 'Merge Selected \& Re-Cluster' para finalizar. Após clique em close.

2: Os agrupamentos podem ser feitos também com a edição de palavras. Se você editar uma palavra no OpenRefine, com uma palavra que já existe na sua rede, ela automaticamente será agrupada. Para isso selecione a coluna e escolha a opção Text $>$ Text Facet. $\mathrm{Na}$ aba onde as palavras serão apresentadas em ordem alfabética você pode identificar palavras que ainda podem ser agrupadas manualmente através da opção de edição do registro.

*Cuidado com os vícios de linguagem, mesmo realizando a desambiguação algumas expressões podem escapar e assim afetar a sua rede de palavras. Para evitar equívocos, quando existir dúvidas, recorra a tabela das entrevistas e localize as palavras através do número do id.

Passo 7: Exportar o arquivo totalmente limpo em 'csv' e preparação da tabela para ser lida pelo Gephi para elaboração da rede de palavras (As colunas da tabela devem ser nomeadas com 'Source' 'Target' 'Type' e a coluna 'Type' deve ser totalmente preenchida com valor 'Undirected'.

Procedimentos do passo 7: (OpenRefine)
1: Após concluir a lapidação exporte a planilha: Clicar em Export,
e exporte com a opção comma-separated value (.csv). Salve o script
final em um documento do Writer para uso posterior.
2: Abra a planilha que foi exportada com o LibreOffice Calc. Nesse
momento é necessário renomear a célula do cabeçalho da primeira
coluna com a palavra Source, a segunda coluna com a palavra Target
e a terceira coluna (que está vazia) inserir no cabeçalho a palavra
Type. A coluna Type deve ser preenchida até o fim com a palavra
Undirected. Salve no formato .csv, denominando esta planilha como
"arestas".

Passo 8: Importar a planilha 'csv' para a tabela de arestas a fim de criar o formato adequado para que o programa possa ler e elaborar a rede frase palavra. A opção 'deixar criar os nós automaticamente' deve estar ligada para que o Gephi consiga realizar a identificação dos nós da rede.

Procedimentos do passo 8: (Gephi)

1: Abra o Gephi.

2: Feche a janela 'Bem Vindo'.

Edson Armando Silva, João Paulo Leandro de Almeida, Joseli Maria Silva, Mayã Polo de Campos 
Técnicas de Análise de Conteúdo: Experiências de Pesquisas Desenvolvidas

pelo Grupo de Estudos Territoriais

3: $\mathrm{Na}$ aba 'Laboratório de Dados' clique em importar planilha e selecione o arquivo arestas.csv

No campo tabela deve estar selecionado Tabela de Arestas. Observe que a opção "criar os nós automaticamente" deve estar ativa.

Clique em Próximo.

Passo 9: Criar uma rede 'dual mode' (o termo 'dual mode' significa que existem duas naturezas de objetos na rede, neste caso frase e palavra).

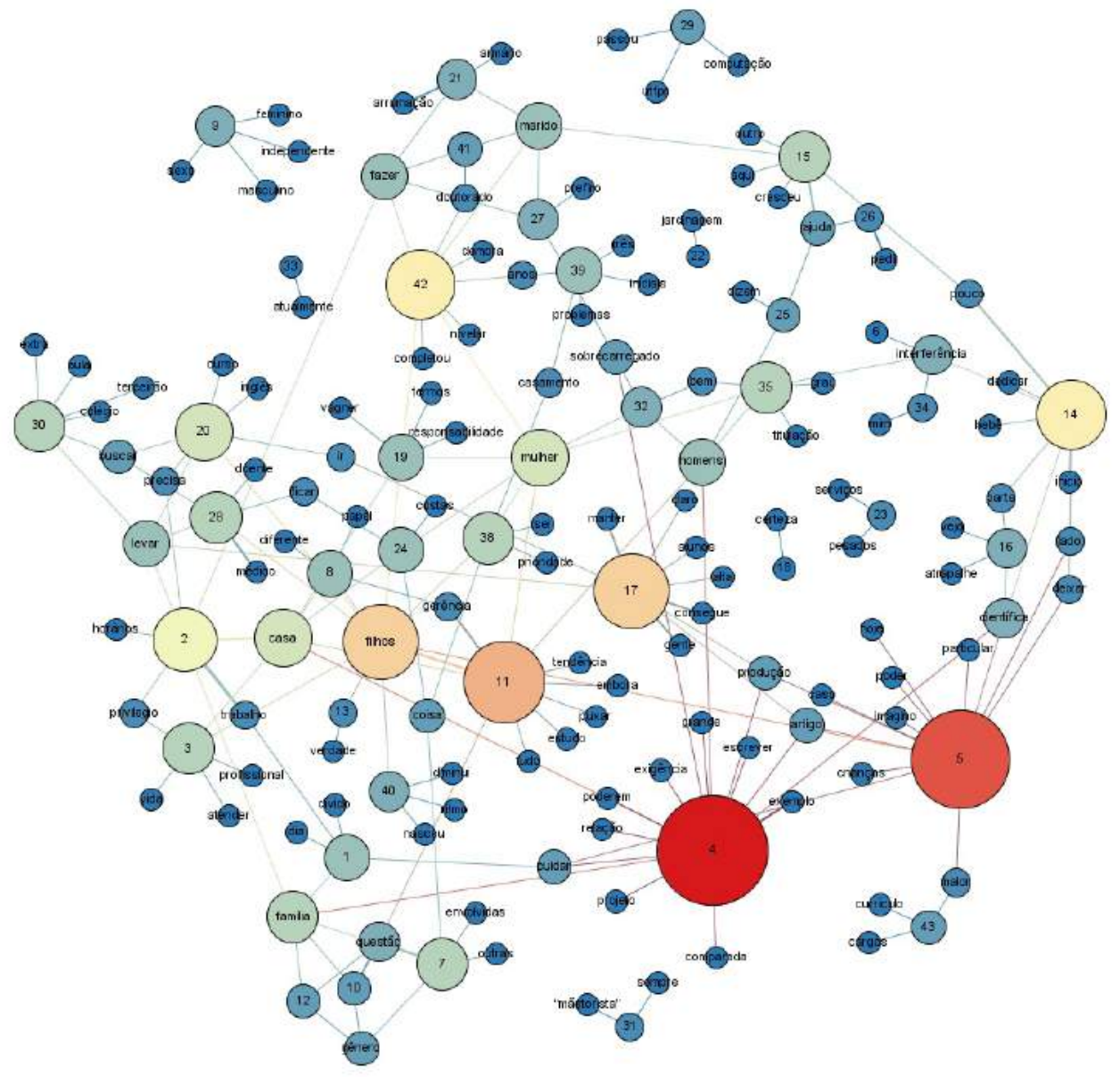

Procedimentos do passo 9: (Gephi)

1: Na aba 'Visão Geral', na parte inferior da janela Grafo clique em 'Atributos' ( 睫) e deixe marcada apenas a opção Id para rotular os nós.

2: Agora na janela Grafo clique em 'Mostrar rótulos de nós' ( $\mathbf{T}$ )

Observe que é possível alterar o tamanho dos rótulos nas guias deslizantes.

3: Na aba 'Estatísticas' execute as funções de cálculo da rede.

4: Na aba 'Partição clique em 'Atualizar' ( e na aba 'Classificação' utilize a opção 'Grau' para caracterizar tamanho proporcional ao peso de cada nó/palavra. 

dados da pesquisa

6: Na janela Visualização clique em 'Atualizar' e efetue as alterações para exportar a imagem

7: Quando estiver de acordo com o desejado clique em 'Exportar' e escolha a melhor extensão para o arquivo.

obs: observe se o arquivo exportado não teve cortes, caso ocorra, efetue esta ação novamente alterando as opções da imagem a ser exportado.

Passo 10: Projetar a rede 'dualmode' frase-palavra em uma rede 'onemode' palavra-palavra. Para isso precisamos criar uma nova coluna de identificação na tabela de nós, denominada NAT, para que o programa possa identificar qual nó é referente a uma frase e qual nó se refere à palavra.

\section{Procedimentos do passo 11: (Gephi + Multimode Networks Transformation Plugin): nós. \\ 1: Retorne para a aba 'Laboratório de dados' e selecione a tabela de}

2: Clique em 'Exportar tabela'. Na nova janela que abrir o separador deve ser 'vírgula' e o campo 'Codificação de caracteres' deve ser 'UTF-8', clique em 'ok'. Selecione o local para salvar e denomine o arquivo .csv como 'nós'.

3: Abra a planilha do OpenOffice Calc.

4: Crie uma nova coluna denominada NAT.

Classifique a coluna Id em ordem crescente, com seleção estendida.

5: Identifique na coluna 'id' as células preenchidas com os números que representam os identificadores das frases, e, ao lado, na coluna 'Nat' preencha com a letra F.

Para as células identificadas contendo palavras, na coluna 'Id', ao lado, na coluna 'Nat' preencha com a letra P.

Salve o arquivo mantendo o formato .csv, conforme exemplo a seguir:

\begin{tabular}{|c|c|c|}
\hline id & label & NAT \\
\hline 1 & 1 & $\mathbf{F}$ \\
\hline 2 & 2 & $F$ \\
\hline 3 & 3 & $\mathbf{F}$ \\
\hline 4 & 4 & F \\
\hline 5 & 5 & $\mathbf{F}$ \\
\hline 6 & 6 & F \\
\hline 7 & 7 & F \\
\hline 8 & 8 & $\mathbf{F}$ \\
\hline sim & sim & $\mathrm{P}$ \\
\hline divido & divido & $P$ \\
\hline dia & dia & $P$ \\
\hline cuidar & cuidar & P \\
\hline familia & familia & $\mathrm{P}$ \\
\hline trabalho & trabalho & $P$ \\
\hline casa & casa & P \\
\hline tento & tento & P \\
\hline privilegiar & privilegiar & $\mathrm{P}$ \\
\hline familia & familia & P \\
\hline não & não & P \\
\hline levar & levar & P \\
\hline trabalho & trabalho & $P$ \\
\hline
\end{tabular}


Passo 11: Explorar o grafo 'onemode' (palavra-palavra).

\section{Procedimentos do passo 11: (Gephi)}

Para criar e explorar as possibilidades interpretativas da rede de palavras aplique os mesmos procedimentos do passo 10. Observe no exemplo abaixo como se pode perceber as concentrações temáticas em torno de alguns núcleos. Neste caso percebe-se claramente nos discursos femininos uma concentração em torno do tema "produção científica", outra concentração em torno do tema "cuidado dos filhos" e outra ainda em torno do "cuidado da casa". Essas concentrações nos dão uma pista para a formulação das primeiras hipóteses interpretativas do conjunto discursivo.

Ao se comparar a rede produzida pelos discursos masculinos com a rede dos discursos femininos revelam-se diferenças muito interessantes. A rede geral se articula em torno do tema do trabalho com destaque para dois núcleos temáticos. Um que reuniu as palavras usadas em torno do tema "trabalho" e outro em torno da "produção 
Técnicas de Análise de Conteúdo: Experiências de Pesquisas Desenvolvidas pelo Grupo de Estudos Territoriais

científica". Note-se que os temas "cuidado dos filhos" e "cuidado da casa" não aparecem no discurso masculino.

Grafo Discurso Feminino (relação/frequência entre palavras)

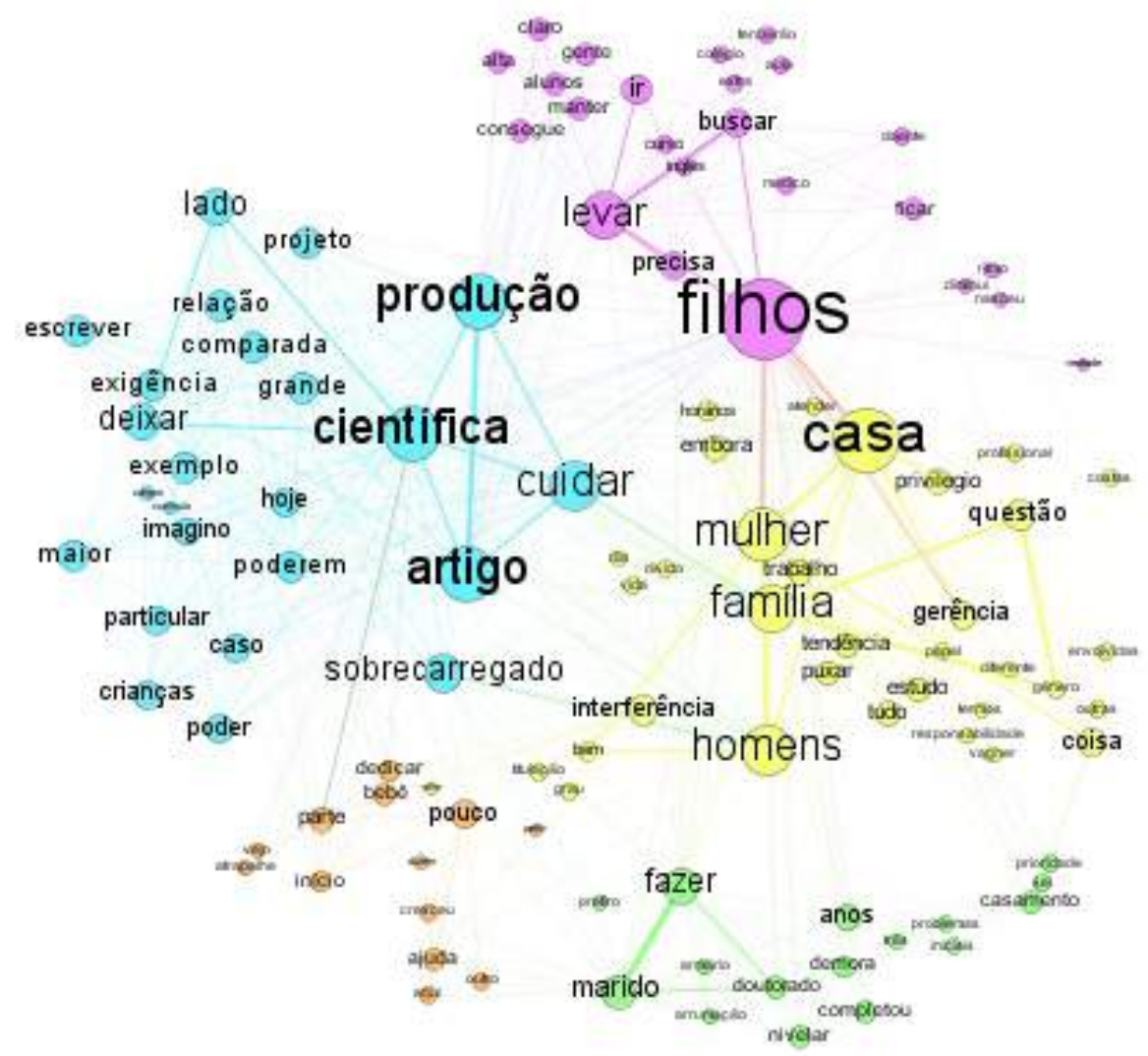

Grafo Discurso Masculino (relação/frequência entre palavras)

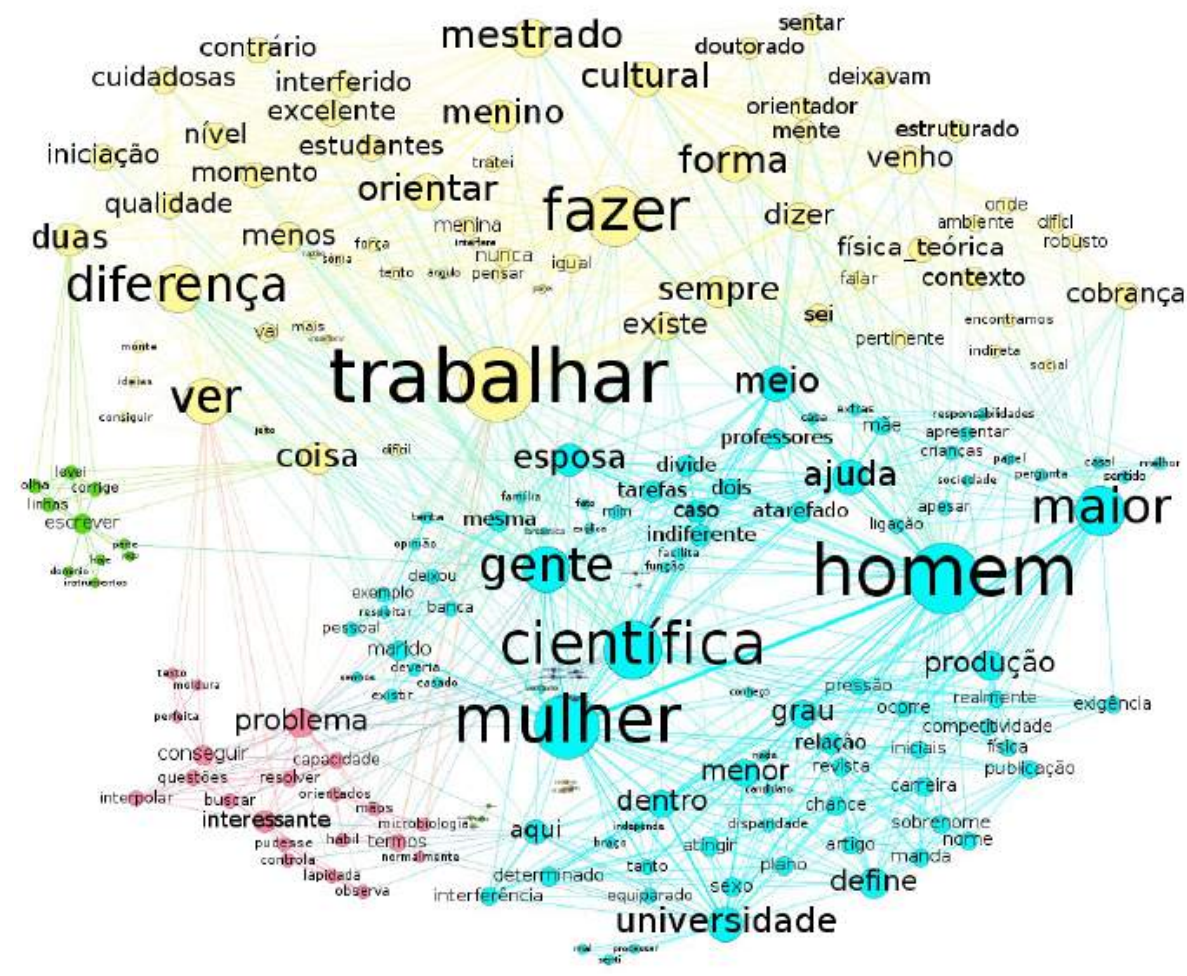

Edson Armando Silva, João Paulo Leandro de Almeida, Joseli Maria Silva, Mayã Polo de Campos 
Técnicas de Análise de Conteúdo: Experiências de Pesquisas Desenvolvidas

pelo Grupo de Estudos Territoriais

\section{Segunda Etapa: A Criação do Mapa Mental}

Esta etapa tem como propozito demonstrar as relações entre a rede de palavras (informação procedente puramente da fala do grupo ou da escrita do documento) e as sub-questões elaboradas pela/o pesquisador/a. O mapa mental articula as questões da pesquisa e as concentrações discursivas para produzir uma árvore categorial capaz de criar uma camada interpretativa da estrutura discursiva. Outras metodologias podem ser agregadas conforme a natureza das questões. (Nesta etapa: $V U E$ ).

Passo 1: Observação da rede de palavras criada na etapa anterior.

Procedimentos do passo 1:

1: Identifique as concentrações temáticas, confrontando-as com as hipóteses da pesquisa para elaborar uma rede de categorias que permitam organizar a interpretação do conjunto dos discursos. Pelo viés geográfico sugerimos que sejam identificadas as espacialidades discursivas e as categorias discursivas.

Passo 2: Organização do Mapa Mental da pesquisa:

Procedimentos do passo 2: (VUE)

1: Abra o VUE (Visual Understanding Environment), para dar o suporte visual necessário para a construção de um mapa conceitual, que no nosso caso, será um mapa de relacionamento entre as categorias que darão suporte à interpretação do conjunto discursivo.

O VUE, é um programa bastante acessível, basta procurar alguns instantes para encontrar a ferramenta que necessitar.

2: Abra o programa e insira um nó com a questão central ${ }^{3}$ da investigação (ou objetivo geral), bem como nós com as sub-questões (ou objetivos específicos). Para isso, clique no retângulo no canto superior do lado esquerdo e crie os quadros clicando e arrastando o mouse.

3: Na etiqueta do quadro, insira a sua pergunta central, bem como as questões específicas.

4: Para personalizar a caixa de diálogo, você deve clicar em cima do quadro com o botão direito do mouse e clicar em paleta de formatação, onde será possível alterar cor, fonte, tamanho.

5: Após esse passo, abra o primeiro grafo geral gerado no Gephi. Esse grafo, em conjunto com a questão central e as questões específicas, devem proporcionar um conjunto de informações que possibilitem ao pesquisador identificar as categorias de análise referente a cada questão específica.

6: Conforme são identificadas as categorias, insira-as no mapa, de acordo com a questão que cada categoria responde.

Sabemos que as categorias muitas vezes estão ligadas a mais de

3 Aprofunde a forma de elaboração das questões em Silva, Silva e Junckes (2009). 
Técnicas de Análise de Conteúdo: Experiências de Pesquisas Desenvolvidas

pelo Grupo de Estudos Territoriais

uma questão, ou podem ser categorias internas a outras e que mesmo assim merecem destaque. Esse momento é próprio de cada fenômeno e cabe ao investigador escolher a melhor forma para representação do mapa de categorias.

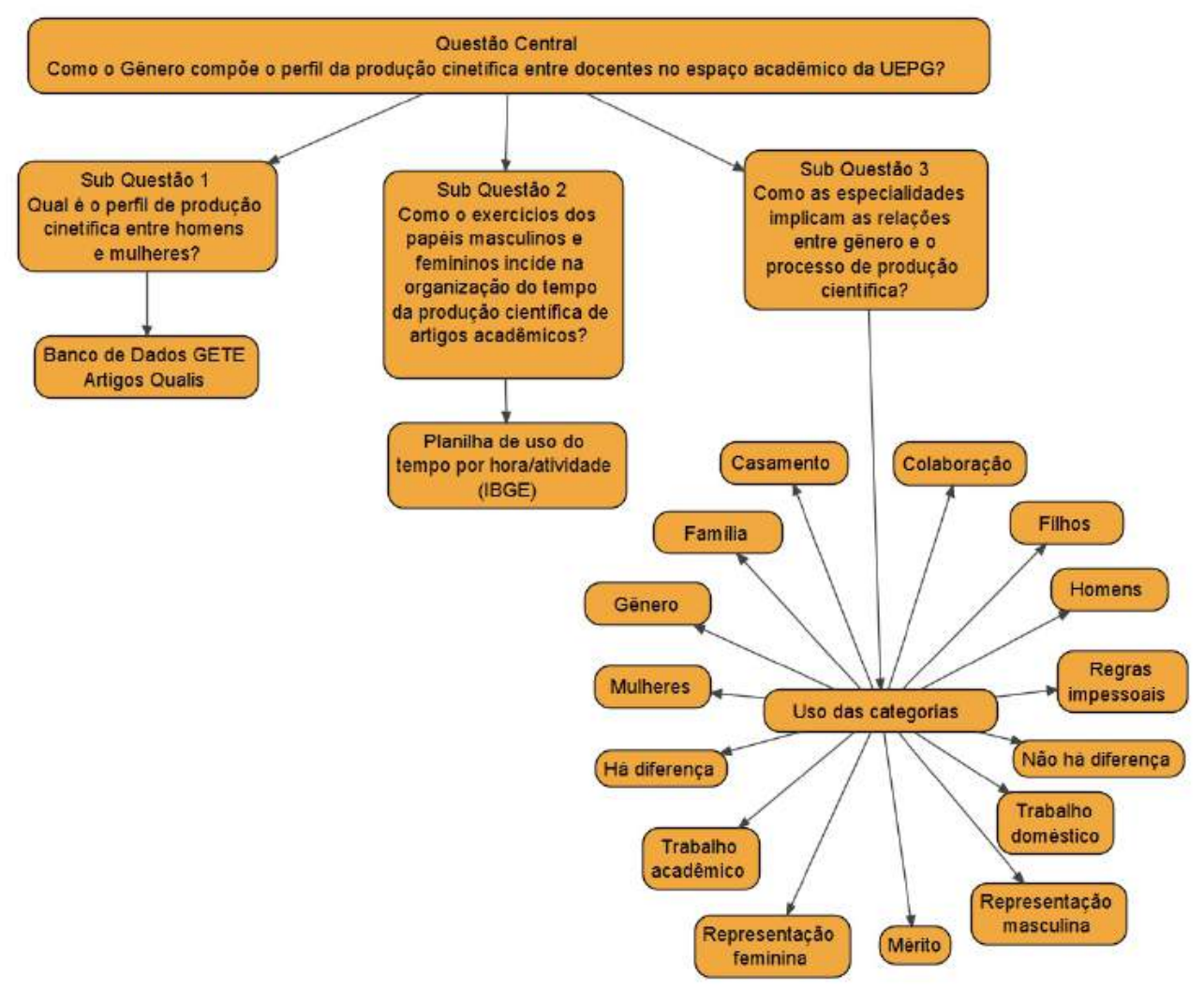

7: Insira as categorias identificadas nos grafos em uma tabela procurando identificar espacialidade discursiva, categoria discursiva e sujeito da relação, inserindo consequentemente na frente da palavra ed, cd e sr.

\section{Terceira etapa: Constituição das Categorias de Sentido}

Nesta etapa o destaque é o papel ativo do pesquisador na constituição das categorias de sentido (Nesta etapa: Pacote $R$ onde terá acesso ao $R Q D A-$ Package for Qualitative Data Analysis e ao SQLITE / Gephi) para chegar na rede semântica.

Passo 1: Criar as categorias do discurso que devem ter relação direta com a questão central e sub-questões elaboradas e ao mesmo tempo potencial explicativo para a rede de palavras criada anteriormente.

Procedimentos do passo 1: (RQDA)

1: Abra o Rstudio

2: Na aba Packages selecione o pacote $R Q D A$

3: Nesta nova janela clique em New Project e selecione o local para salvar o projeto.

Edson Armando Silva, João Paulo Leandro de Almeida, Joseli Maria Silva, Mayã Polo de Campos 
Técnicas de Análise de Conteúdo: Experiências de Pesquisas Desenvolvidas pelo Grupo de Estudos Territoriais

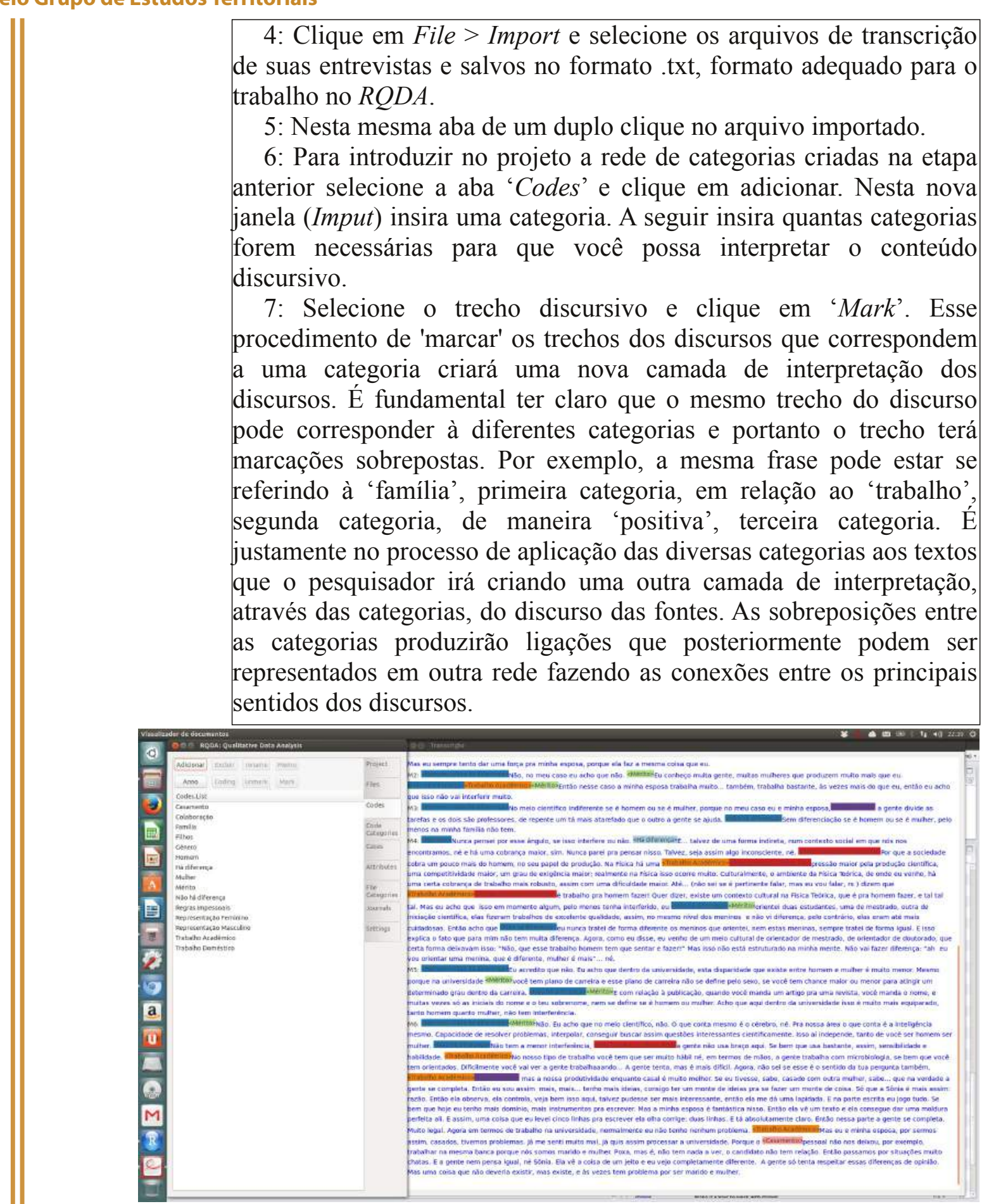

O programa $R Q D A$ permitirá uma série de procedimentos de análise. $\mathrm{O}$ agrupamento de todas as expressões correspondentes a uma categoria, a seleção de trechos com algumas formas específicas de sobreposição, etc. Entretanto para conseguirmos um grafo que expresse a estrutura semântica do conjunto discursivo devemos exportar os textos com suas marcações e o submetermos novamente aos procedimentos para a produção de novas redes.

Edson Armando Silva, João Paulo Leandro de Almeida, Joseli Maria Silva, Mayã Polo de Campos 
Técnicas de Análise de Conteúdo: Experiências de Pesquisas Desenvolvidas

\section{pelo Grupo de Estudos Territoriais}

Passo 2: Extrair do banco de dados as informações armazenadas do processo de marcação das categorias gerando a tabela da relação entre categoria - palavras.

Procedimentos do passo 2: $(R Q D A)$

1: Após categorizar toda a entrevista abra o SQLite Browser

2: Clique em Connectd Database

3: Na aba Execute $S Q L$ Insira o comando

Se nenhuma categoria foi apagada e suas entrevistas estão em apenas um arquivo txt:

SELECT name, seltext FROM freecode, coding WHERE freecode.id=coding.cid

Atenção: Caso alguma categoria tenha sido apagada faça o seguinte: SELECT name, seltext FROM freecode, coding WHERE freecode.id=coding. . $i d$ AND freecode.status $=1$

Caso ainda seu projeto tenha sido criado com diversos arquivos de transcrição e você queira selecionar as marcações de algum deles basta acrescentar a cláusula $A N D$ coding. fid $=3$ (aonde 3 é o identificador do arquivo que você pretende selecionar).

4: Clique em Actions > "Save Result (CSV) to" e denomine esta tabela como categorias_trechos. O resultado deve ser algo como o exemplo abaixo:

\begin{tabular}{|c|c|}
\hline Categoria & Palavras \\
\hline Homem & $\begin{array}{l}\text { Nào. Acho que não né. Tem algumas } \\
\text { vantagens... Eu ajudo bastante em casa, mas } \\
\text { sempre a mãe tem responsabilidades extras né. } \\
\text { As crianças têm uma ligação um pouco maior } \\
\text { com a mãe, apesar de eu sempre me apresentar } \\
\text { pra ajudar. Então eu acho que ajuda, facilita um } \\
\text { pouco para mim né ser homem em função disso } \\
\text { né. Mas eu sempre tento dar uma força pra } \\
\text { minha esposa, porque ela faz a mesma coisa que } \\
\text { eu. }\end{array}$ \\
\hline Mulher & $\begin{array}{l}\text { Sim, eu divido o meu dia entre cuidar da familia } \\
\text { e o trabalho. Então quando eu tô em casa tento } \\
\text { privilegiar a familia e não levar trabalho para } \\
\text { casa, não precisar fazer trabalho fora dos } \\
\text { horánios em que eu teria que trabalhar. E quando } \\
\text { minhas filhas tão em casa eu privilegio as duas } \\
\text { do que atender a vida profissional [...] } \\
\text { Sobrecarregam porque a nossa exigência com } \\
\text { relação à produção científica é grande, eu sou } \\
\text { comparada com homens, por exemplo, quando } \\
\text { estão em casa às vezes nào estão cuidando da } \\
\text { familia pra poderem escrever um artigo, um } \\
\text { projeto, por exemplo. No meu caso em } \\
\text { particular, eu deixo o artigo de lado pra poder } \\
\text { cuidar das crianças, então se eu nào tivesse } \\
\text { filhos, eu imagino que minha produtividade } \\
\text { cientifica seria muito maior do que hoje. }\end{array}$ \\
\hline Família & $\begin{array}{l}\text { Acho que é diferente você ter filho, ter esse } \\
\text { papel, ter uma casa pra gerenciar e você não } \\
\text { ter... independente do sexo ser masculino ou } \\
\text { feminino. }\end{array}$ \\
\hline
\end{tabular}


Técnicas de Análise de Conteúdo: Experiências de Pesquisas Desenvolvidas pelo Grupo de Estudos Territoriais

Passo 3 (LibreOffice / OpenRefine): Neste ponto você pode repetir todos os procedimentos indicados na etapa 1 como: retirar pontuação em geral, padronizar as palavras em letras minúsculas, retirar termos não significativas (stopwords), unificar termos com mesmo radical, separar palavras e assim por diante. Lembre-se que você tem a vantagem de já possuir um script preparado especialmente para o seu conjunto discursivo de maneira que esses procedimentos podem ser completamente automatizados.

Passo 4 (OpenRefine): Exportar o arquivo totalmente limpo em 'csv' e preparação da tabela para ser lida pelo Gephi para elaboração da rede de categorias e palavras (As colunas da tabela devem ser nomeadas com 'Source' 'Target' 'Type' e a coluna 'Type' deve ser totalmente preenchida com valor 'Undirected'.

Passo 5 (Gephi): Importar a planilha 'csv' para a tabela de arestas a fim de criar o formato adequado para que o programa possa ler e elaborar a rede categoria - palavra. A opção 'deixar criar os nós automaticamente' deve estar ligada para que o Gephi consiga realizar a identificação dos nós da rede.

Passo 6 (Gephi): Exportar o grafo 'dualmode' (categoria - palavra).

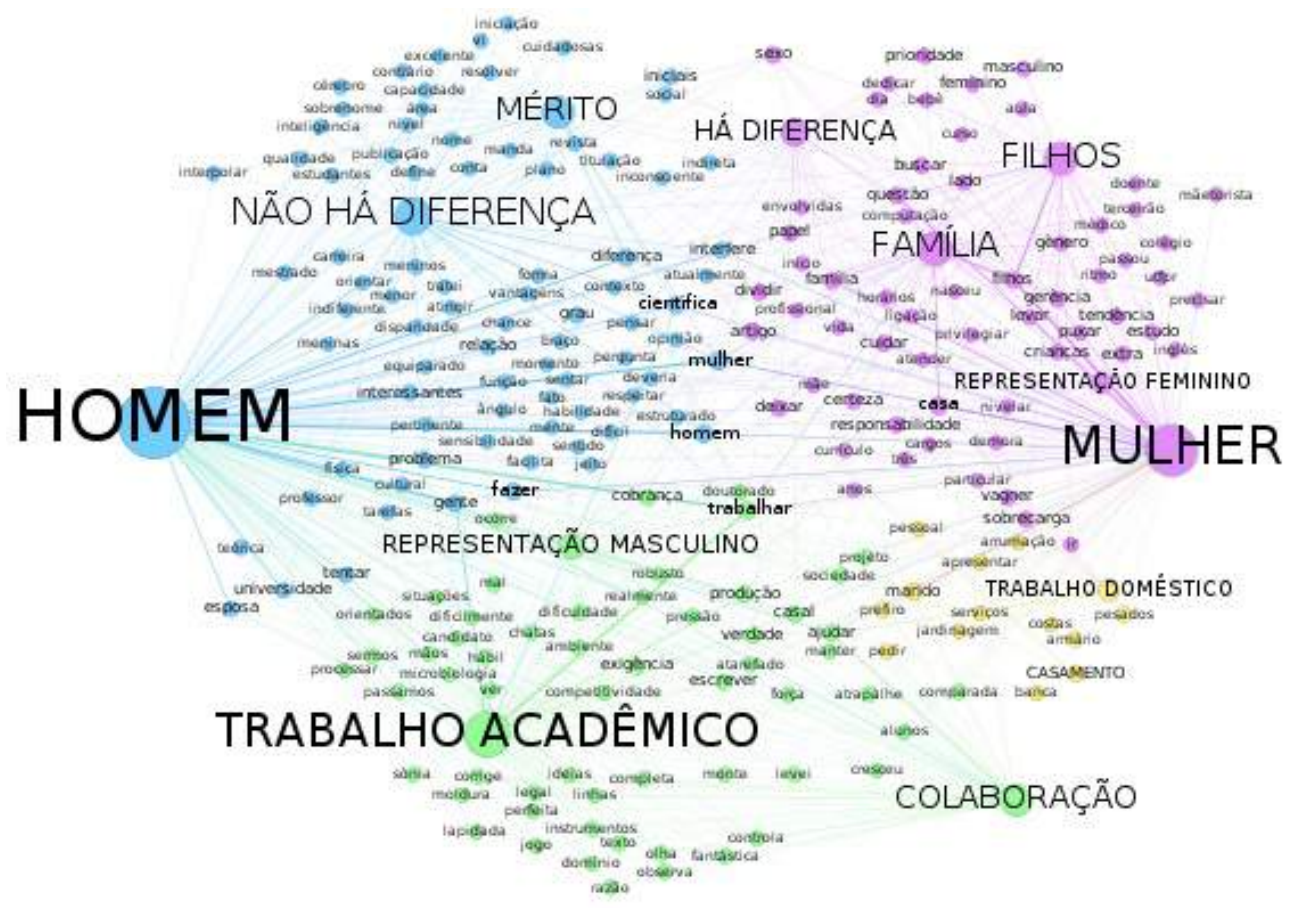

Passo 7 (Gephi + Multimode Networks Transformation Plugin): Exportar a tabela de nós a partir do Gephi para preparação da planilha 'csv' para a coversão 'dualmode' (categoria - palavra) em 'onemode' (categoriacategorias). No editor de planilha criar uma coluna com 'NAT' (que significa a natureza do nó) à direita em seguida do ID e Label. Para os nós referentes às categorias colocar ' $\mathrm{C}$ ' na respectiva célula da coluna 'NAT'. Para os nós referentes às palavras colocar ' $\mathrm{P}$ ' na respectiva célula da coluna 'NAT'. O resultado deve ser parecido com a tabela abaixo:

Edson Armando Silva, João Paulo Leandro de Almeida, Joseli Maria Silva, Mayã Polo de Campos 
Técnicas de Análise de Conteúdo: Experiências de Pesquisas Desenvolvidas pelo Grupo de Estudos Territoriais

\begin{tabular}{|c|c|c|}
\hline id & label & NAT \\
\hline Homem & Homem & C \\
\hline Mulher & Mulher & C \\
\hline Família & Família & C \\
\hline Filhos & Filhos & C \\
\hline Colaboração & Colaboração & C \\
\hline Casamento & Casamento & C \\
\hline Mérito & Mérito & C \\
\hline Fazer & Fazer & C \\
\hline Casa & Casa & C \\
\hline Trabalho & Trabalho & $\mathrm{C}$ \\
\hline sim & sim & $\mathrm{P}$ \\
\hline divido & divido & $\mathrm{P}$ \\
\hline dia & dia & $\mathrm{P}$ \\
\hline cuidar & cuidar & $\mathrm{P}$ \\
\hline família & família & $\mathrm{P}$ \\
\hline trabalho & trabalho & $\mathrm{P}$ \\
\hline casa & casa & $\mathrm{P}$ \\
\hline tento & tento & $\mathrm{P}$ \\
\hline privilegiar & privilegiar & $\mathrm{P}$ \\
\hline família & família & $\mathrm{P}$ \\
\hline não & não & $\mathrm{P}$ \\
\hline levar & levar & $\mathrm{P}$ \\
\hline trabalho & trabalho & $\mathrm{P}$ \\
\hline & & \\
\hline
\end{tabular}

Passo 8 (Gephi): Projetar a rede dualmode (categoria-palavra) para uma rede 'onemode' (categoria-categoria). Importar a planilha 'csv' para a tabela de nós a fim de criar o identificador NAT que permita ao plugin de transformação projetar a rede "dualmode" para uma rede "onemode". Os procedimentos são os mesmos do passo 11 com a pequena diferença que na aba 'Multimode Networks Projection' (instalada como plugin do Gephi) ao se clicar 'Load atributes' na caixa Attribute type e selecionando-se 'Nat' deve-se preencher a caixa Left matrix selecione com C-P e a caixa Right matrix com P-C.

Passo 9 (Gephi): Explorar o grafo 'onemode' (categoria-categoria)

Ao se trabalhar o layout do grafo com os atributos de tamanho e cor para expressar as relações mais importantes no grafo e ao se calcular a modularidade para destacar as comunidades de nós (neste caso as categorias) com as relações mais densas, se produzirá um grafo que expressa a estrutura discursiva do conjunto das fontes trabalhadas. Algo semelhante ao exemplo abaixo:

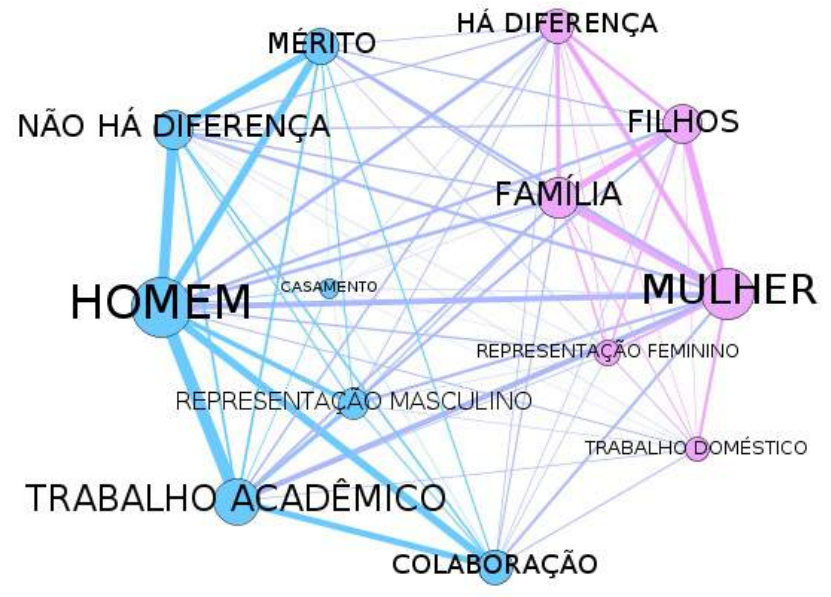

Edson Armando Silva, João Paulo Leandro de Almeida, Joseli Maria Silva, Mayã Polo de Campos 
Técnicas de Análise de Conteúdo: Experiências de Pesquisas Desenvolvidas

pelo Grupo de Estudos Territoriais

Enfim, você tem uma rede semântica que possibilita compreender a estrutura discursiva produzida na relação com as pessoas que foram entrevistadas, as categorias e os significados das relações entre elas. $\mathrm{O}$ grafo demonstra as relações estruturais entre as categorias e constitui o critério de retorno aos textos para recuperar a voz das fontes. Nesta fase, não se trata mais de selecionar intuitivamente os trechos que correspondem às minhas hipóteses (ou desejos) mas de levantar os trechos do discurso que melhor ilustram as tendências estruturais apontadas no grafo.

\section{Referências}

ACKERLY, Brooke; TRUE, Jacqui. Doing feminist research in political \& social science. New York: Palgrave Macmillan, 2010.

BARDIN, Laurence. 1977. Análise de Conteúdo. Lisboa: Edições 70.

CAMPOS, Mayã Pólo. Mulheres vítimas de violência sexual e os significados de suas experiências corporais e espaciais: teu corpo é o espaço mais teu possível. 2016. Dissertação (Mestrado em Gestão do Território) - Programa de Pós-Graduação em Geografia, Universidade Estadual de Ponta Grossa, Ponta Grossa.

HARAWAY, Donna. Situated knowledges: the science question in feminism and the privilege of partial perspective. Feminist Studies, v. 14, n. 3, p. 575 $599,1988$.

PINTO, Vagner André Morais. O gênero enquanto componente da produção científica no espaço acadêmico da UEPG. 2014. Monografia (Licenciatura em Geografia) - Universidade Estadual de Ponta Grossa, Ponta Grossa.

PRZYBYSZ, Juliana. Nem santas nem putas, apenas mulheres: espacialidades de mulheres prostitutas de baixa renda no exercício de maternagens em Ponta Grossa. 2017. Tese (Doutorado em Geografia) Programa de Pós-Graduação em Geografia, Universidade Estadual de Ponta Grossa, Ponta Grossa.

ROSSI, Rodrigo. Espacialidade carcerária e a instituição de masculinidades entre homens jovens egressos em Ponta Grossa, Paraná. 2017. Tese (Doutorado em Geografia) - Programa de Pós-Graduação em Geografia, Universidade Estadual de Ponta Grossa, Ponta Grossa.

SILVA, Edson Armando; SILVA Joseli Maria. Ofício, Engenho e Arte: Inspiração e técnica na análise de dados qualitativos. Revista Latinoamericana de Geografia e Gênero, v. 7, n. 1, p. 132 - 154, 2016.

SILVA, Joseli Maria; SILVA, Edson Armando; JUNCKES, Ivan Jairo. Construindo a ciência: elaboração crítica de projetos de pesquisa. Curitiba: Pós-Escrito, 2009.

SILVA, Joseli Maria; RODÓ-DE-ZÁRATE, Maria; ORNAT, Marcio Jose. Age, 
Técnicas de Análise de Conteúdo: Experiências de Pesquisas Desenvolvidas

pelo Grupo de Estudos Territoriais

sexuality and intersectionalities: spatial experiences of Brazilian travestis and transwomen aging process. (forthcoming).

Sites que disponibilizam os softwares utilizados:

https://pt-br.libreoffice.org/

http://openrefine.org/

https://gephi.org/

http://vue.tufts.edu/

https://www.r-project.org/

https://sqlite.org/

\section{Recebido em 08 de setembro de 2017. \\ Aceito em 05 de novembro de 2017.}

Edson Armando Silva, João Paulo Leandro de Almeida, Joseli Maria Silva, Mayã Polo de Campos 